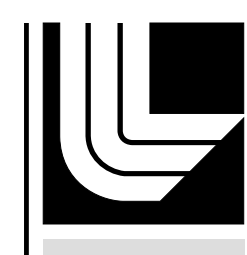

LAWRENCE LIVERMORE N A T IO N A L LABORATORY

\title{
Documentation of a Model Action Plan to Deter Illicit Nuclear Trafficking
}

D.K. Smith, M.J. Kristo, S. Niemeyer, G.B. Dudder

July 28, 2006

Methods and Applications of Radioanalytical Chemistry MARC VII

Kona, HI, United States

April 2, 2006 through April 7, 2006 
This document was prepared as an account of work sponsored by an agency of the United States Government. Neither the United States Government nor the University of California nor any of their employees, makes any warranty, express or implied, or assumes any legal liability or responsibility for the accuracy, completeness, or usefulness of any information, apparatus, product, or process disclosed, or represents that its use would not infringe privately owned rights. Reference herein to any specific commercial product, process, or service by trade name, trademark, manufacturer, or otherwise, does not necessarily constitute or imply its endorsement, recommendation, or favoring by the United States Government or the University of California. The views and opinions of authors expressed herein do not necessarily state or reflect those of the United States Government or the University of California, and shall not be used for advertising or product endorsement purposes. 
Log Number: 194

Documentation of a model action plan to deter illicit nuclear trafficking

\author{
D.K. Smith \\ smith24@1lnl.gov \\ M.J. Kristo \\ kristo2@1lnl.gov \\ S. Niemeyer \\ niemeyer1@1lnl.gov \\ Lawrence Livermore National Laboratory, Livermore, CA 94550 USA \\ G.B. Dudder \\ gordon.dudder@pnl.gov \\ Pacific Northwest National Laboratory, Richland, WA 99352 USA
}

Key words: nuclear trafficking, nuclear attribution, nuclear forensics 


\title{
Documentation of a model action plan to deter illicit nuclear trafficking
}

\author{
D.K. Smith, M.J. Kristo, S.Niemeyer \\ Lawrence Livermore National Laboratory, Livermore, CA 94550 USA \\ G.B. Dudder \\ Pacific Northwest National Laboratory, Richland, WA 99352 USA
}

Theft, illegal possession, smuggling, or attempted unauthorized sale of nuclear and radiological materials remains a worldwide problem. The Nuclear Smuggling International Technical Working Group (ITWG) has adopted a model action plan to guide investigation of these cases through a systematic approach to nuclear forensics. The model action plan was recently documented and provides recommendations concerning incident response, collection of evidence in conformance with required legal standards, laboratory sampling and distribution of samples, radioactive materials analysis, including categorization and characterization of samples, forensics analysis of conventional evidence, and case development including interpretation of forensic signatures.

\section{INTRODUCTION}

Nuclear forensics and nuclear attribution have become increasingly important tools in the fight against illegal trafficking in nuclear and radiological materials. As trafficking of these materials has increased during the last decade, so has the need to develop tools and procedures that allow insight into the movement of contraband and those involved in these illegal activities. Nuclear forensics and attribution is an emerging cross-disciplinary science that combines elements of nuclear and radiochemistry, 
analytical chemistry, materials science, nuclear physics, nuclear engineering, and environmental science. While recent publications have begun to describe this field, less attention has been focused on developing an accepted, systematic approach to nuclear forensic and attribution investigation ${ }^{1,2}$. Absent such an approach, the international community, including law enforcement, first responders, and governmental policy makers, have requested assistance in the development of reliable, accepted procedures for responding to incidents involving the interdiction of nuclear and radiological materials. This paper is a summary of a larger technical report delivered to the International Atomic Energy Agency as a framework for international nuclear forensics support ${ }^{3,4}$.

\section{EXPERIMENTAL}

\section{Definitions}

Nuclear attribution is a process to identify the source of nuclear or radioactive materials used in illegal activities; to determine the point-of-origin and routes of transit involving contraband materials, and to ultimately contribute to the successful prosecution of those responsible. Inputs essential to nuclear attribution include 1) results from nuclear and traditional forensic analyses, 2) scientific understanding of radiochemical and environmental signatures, 3) knowledge of the methods of production of nuclear materials, the civilian nuclear fuel cycle, and the nuclear weapons development pathway, and 4) information from law enforcement and intelligence sources. Through fusion of all relevant forms of information pertaining to nuclear trafficking; attribution enables data to be readily accessed, analyzed, and interpreted to formulate an appropriate law enforcement or national security response. 
Nuclear forensics is the analysis of interdicted illicit nuclear or radioactive materials and any associated materials to provide evidence for nuclear attribution. Potential signatures may include isotopic, chemical, morphological, or physical signatures from the nuclear or radiological materials, as well as traditional forensic signatures including fingerprints, DNA, explosive residues, hair, fibers, and pollen. The goal of nuclear analysis is to identify forensic indicators in the samples or the allied environment, e.g. containers or packaging. These indicators arise from known relationships between materials characteristics and process history. For this reason, nuclear forensics is dependent upon a detailed understanding of the nuclear fuel cycle and the associated signatures that accompany concentration, enrichment, fabrication, and irradiation history of nuclear and radiological materials.

\section{Sources of nuclear and radioactive materials}

Nuclear materials can be categorized as: special nuclear materials (SNM), reactor fuel, and commercial radioactive sources (see Table 1).

SNM makes an especially attractive target for nations and terrorist organizations intent on developing a nuclear weapon, because possession of sufficient amounts of SNM eliminates the necessity of developing the advanced technology required for isotopic enrichment of uranium or plutonium separation. Radioactive isotopes are useful sources of radioactivity for medical diagnostics and therapy, non-destructive analysis of materials, sterilization of medical equipment and food, and generation of electricity in remote locations. The significant level of radioactivity in many commercial radioactive 
sources and spent reactor fuel makes them attractive components of a radiological dispersal device (RDD) or so called "dirty bomb".

\section{Nuclear trafficking and the emerging nature of the problem}

The International Atomic Energy Agency has maintained an Illicit Trafficking Database (ITDB) on cases of unauthorized use, transport, and possession of nuclear and radioactive materials since 1995 . There has been a significant increase in the number of reported nuclear smuggling cases since 1991. Between 1995 and the end of 2004, more than 650 illicit trafficking incidents have been confirmed by 82 participating member states.

The terrorist attacks of September 11, 2001, have focused world attention on terrorist groups, their aims, and their methods. Although it is difficult to predict the future course of illicit trafficking in nuclear and radiological materials; increasingly, these incidents are viewed as significant threats that merit the development of national and international forensic and attribution response capabilities.

\section{International cooperation}

Many international forensics laboratories are already cooperating to develop common technical strategies and databases that catalogue nuclear processes for use in nuclear attribution. The Nuclear Smuggling International Technical Working Group (ITWG) was formed in 1995 to foster international cooperation in combating illicit trafficking of nuclear materials. More than 28 nations and organizations have participated in ten international meetings and two round-robin analytical trials to-date ${ }^{5}$. In 2004 the ITWG Nuclear Forensics Laboratories (INFL) was established to develop 
accepted and common protocols for the collection of evidence and laboratory investigations, prioritize techniques and methods for forensic analyses for nuclear and non nuclear samples, inter-laboratory forensic exercises, and development of forensic databanks to assist in interpretation, and to provide technical assistance for requesting countries.

\section{RESULTS AND DISCUSSION}

\section{Nuclear forensic model action plan}

A graded level of response is appropriate following both the notification or detection of an undeclared and suspect radioactive source, and the initial response and evaluation by first responders.

1) An operational response by first responders where there is no health hazard, no security implications, and no proliferation threat;

2) A tactical response required by more serious cases where a health hazard is identified or a criminal act is suspected;

3) A strategic response calls on the activation of a district or national emergency response plan because of a significant potential hazard to the environment or public.

Nuclear forensic investigations begin immediately following the interdiction of a suspect radioactive source. It is particularly important when there is an indication of possible criminal activity. Because nuclear forensics is focused on developing information necessary to respond to acts of trafficking, the forensic investigations are required to answer specific questions raised by law enforcement. Nuclear forensic investigations must be conducted consistent with the following requirements:

1. Law enforcement authorities secure the site of the interdiction. 
2. Trained and equipped first responders confirm the nuclear or radioactive nature of the material and determine whether a potential nuclear or radiological hazard exists.

3. The lead agency is notified to initiate the action plan.

4. At the scene where the nuclear or radioactive materials are discovered

- A health physics examination is required to determine the occupational and public radiation hazard.

- Law enforcement response to check for hidden explosives and preservation of evidence, including initiation of chain-of-custody procedures in conformance with the rules of evidence.

- On-site categorization of seized material using mobile non-destructive analysis.

- Secure and safe storage of evidence before transport to the nuclear forensics laboratory.

5. At the specialized national nuclear forensics laboratory:

- Further examination of the sample material for hidden explosives before unpacking.

- Preservation of nuclear forensic evidence and classical forensic analysis of nonradioactive material.

- Detailed investigation contingent upon the laboratory's capabilities (e.g., visual, physical characterization, sub-sampling, analysis of chemical, isotopic and morphological properties).

- Data interpretation from the specialized nuclear forensics laboratory should elucidate the processes used to create or manufacture the material. From this interpretation, attribution of the origin of the material is possible. 
6. If the national nuclear forensics laboratory does not have the necessary capabilities for the required analysis, that sample may be shipped to an appropriately equipped nuclear forensics laboratory such as one affiliated with the INFL.

7. Analytical results are compared with an appropriate nuclear forensics database, possibly resulting in further investigations.

8. An analytical "expert opinion" of the analyzed seized material is drafted for the national law enforcement authorities. A nuclear forensics examiner should help prepare the expert opinion.

9. A national legal authority - through a lead federal agency - evaluates all the evidence.

10. If the evidence can support a prosecution, the national legal authority may file criminal charges.

11. At the conclusion of the litigation, a competent authority will arrange for the final disposition of the seized material.

In this paper, the above measures are grouped and discussed in four categories. (Incident response and nuclear forensics laboratory sampling and distribution are also necessary elements but are not described further in this paper ${ }^{3,4}$.)

- Nuclear forensic analysis

- Traditional forensic analysis

- Nuclear forensic interpretation

- Knowledge bases

\section{Nuclear forensic analysis}

Nuclear forensics does not lend itself to routine procedures that can be universally applied to all evidence. Rather, it involves an iterative approach, in which the results 
from one analysis are used to guide the selection of subsequent analyses. In this way, radioactive materials analysis applied to nuclear forensics proceed in a manner not unlike that of traditional forensic analysis. It is important to emphasize that all sampling and analysis must be performed with strict attention to procedures for both the preservation of evidence and maintaining the chain-of-custody. The sampling process can equally extract and obliterate evidence. Many of the analytical tools used in radioactive materials analysis are destructive in that they may consume some amount of a sample during analysis. The proper selection and sequencing of analyses is critical in preventing the possible destruction of evidence.

The nuclear forensic examiner has a wide array of analytical tools to use for detecting signatures in radioactive material. These individual techniques can be sorted into three broad categories: bulk analysis tools, imaging tools, and microanalysis tools. Bulk analysis tools, including inductively coupled plasma mass spectrometry and x-ray fluorescence analysis allow the forensic scientist to characterize the elemental and isotopic composition of the radioactive material as a whole. Imaging tools consist of optical, scanning, and transmission electron microscopy that provide high magnification images or maps of the material which can also confirm sample homogeneity or heterogeneity. If imaging analysis confirms that the sample is heterogeneous, then microanalysis tools, including electron beam energy dispersive analysis can quantitatively or semi-quantitatively characterize the individual constituents of the bulk material. 
Table II shows the generally accepted sequence of analysis, prioritized into techniques that should be performed within 24 hours, one week, or two months from arrival at the nuclear forensics laboratory.

\section{Traditional forensic analysis}

Traditional forensic analysis, like radioactive materials analysis, can be an iterative process, in which the results from one analysis are used to guide the selection of subsequent analyses. Unlikely and apparently unrelated evidence often are key to the successful prosecution of a case. Once again, all sampling and analysis must be in conformance with procedures for the preservation of evidence and chain of custody. The sampling process could contaminate or destroy some evidence while pursuing other evidence. The collection of traditional forensic evidence on radioactively contaminated materials must also be performed in a manner consistent with sound radiological safety practices.

The variety of traditional forensic evidence, as well as the methods of collection and evaluation, is almost limitless. For example, evidence such as tissue, hair, fingerprints, and shoeprints can often associate a specific individual with a specific place or object. The analysis of fibers, pollen, or chemical substances found at the incident scene can provide information about motives or transportation routes. Documentary evidence provides useful information not only in the content of the communication itself, but also in the incidental details of its creation (paper, ink, film type, extraneous noises, accents).

In keeping with the described procedures for collection of radioactive evidence, the international community has also agreed upon a common sequence for traditional 
evidence collection. Table II shows that the collection of fingerprint and fiber evidence should occur within the first 24 hours after sample receipt. The chemical analysis of other evidence by techniques, such as gas chromatography/mass spectrometry (GC/MS), may occur up to two months after the recovery of evidence. Priority should be given to the collection of more individualized signatures (DNA or hair) or those more sensitive to environmental degradation (HEU residue).

\section{Nuclear forensic interpretation}

Signatures are unique physical, chemical, elemental, and isotopic characteristics that distinguish a given nuclear or radiological material. These signatures enable the identification of the processes that created the material, aspects of the subsequent history of the material, and potentially the locations where the material originated. Two important approaches to delineating signatures are: 1) discovery using an empirical approach through the systematic analysis of nuclear and radiological materials, and 2) modeling based on the chemistry and physics of nuclear processes.

Physical characteristics of the material include the texture, size, and shape of solid objects and the particle size distribution of powder samples. For example, the dimensions of a fresh nuclear fuel pellet are often unique to a given manufacturer. The morphology of the uranium oxide particles comprising a fuel pellet, including inclusions or occlusions, can be indicative of the manufacturing process.

Chemical characteristics of the material include the exact chemical composition

of the material or the association of unique molecular components. For example, uranium oxide can be found in many different forms, e.g., $\mathrm{UO}_{2}, \mathrm{U}_{3} \mathrm{O}_{8}$, or $\mathrm{UO}_{3}$, each of which can be found at various points in the uranium fuel cycle. The association of some organic 
compounds, such as certain light kerosene oils or tributyl phosphate, with the nuclear material can be indicative of a reprocessing operation.

Elemental signatures of the material include the determination of major, minor, and trace elements in the material. Major elements help define the identity of the nuclear material, but minor elements, such as erbium or gadolinium that serve as burnable reactor fuel poisons or gallium that serves as a phase stabilizer for plutonium metal, also help define its origin. Trace elements can also prove to be indicative of a process, e.g., Fe and $\mathrm{Cr}$ residues from stainless steel tooling or $\mathrm{Ca}, \mathrm{Mg}$, or $\mathrm{Cl}$ residues from a water-based cleaning process.

Isotopic signatures of the material include fission or neutron-capture products indicative of irradiation in a nuclear reactor. The isotopes provide insight into reactor type and operating conditions. Other isotopes are decay products. For example, ${ }^{230} \mathrm{Th}$ is a decay product of ${ }^{234} \mathrm{U}$ and ${ }^{235} \mathrm{U}$ is a decay product of ${ }^{239} \mathrm{Pu}$. Because radioactive isotopes decay at a rate determined by the half-life of the parent isotope, the relative amounts of decay products and parent isotopes can be used to determine the "age" of the material (i.e., the time since the parent isotope was last chemically separated from its decay products).

\section{Knowledge bases of nuclear processes}

Knowledge bases of nuclear processes and nuclear forensic data are necessary for effective interpretation of the production methods, point of origin, and transit of nuclear materials throughout the world. The ability to compare signatures with existing knowledge and data is central to the interpretation process. Open as well as proprietary 
knowledge bases are presently maintained by a variety of international, national, and nongovernmental entities. Current efforts are underway to develop and organize databases to specifically catalogue nuclear processes for use in nuclear forensics.

Comparative analyses between interdicted material and archived samples are imperative. These analyses allow the nuclear forensic expert to establish connections between the interdicted material and archived material or between the processes used to create them. Sample archives can include "real world" nuclear forensic samples, reactor fuel stock, other nuclear materials, and industrial radiological sources.

\section{CONCLUSIONS}

A documented model action plan provides guidance to requesting governments and response organizations on nuclear forensic analysis, traditional forensic analysis, nuclear forensic interpretation, and knowledge bases to conduct a nuclear forensic investigation. The sharing of a comprehensive international plan for nuclear forensics is essential to deter illicit trafficking.

Work performed under the auspices of the U.S. Department of Energy by the University of California Lawrence Livermore National Laboratory under Contract W-7405-Eng-48.

\section{REFERENCES}

1. K.J. MOODY, I.D. HUTCHEON, P.M. GRANT Nuclear Forensic Analysis. CRC Press, 2005.

2. K. MAYER, M. WALLENIUS, I. RAY The Analyst 130 (2005) 433. 
3. M.J. KRISTO, D.K. SMITH, S. NIEMEYER, G.B. DUDDER Model Action Plan for Nuclear Forensics and Attribution, UCRL-TR-202675 Lawrence Livermore National Laboratory, 2004.

4. Nuclear Forensics Support. Nuclear Safety Series No. 2. International Atomic Energy Agency, Vienna, 2006.

5. G.B. DUDDER, R.C. HANLEN, G.M.J. HERBILLON International technical working group round robin tests in Advances in Destructive and Non-Destructive Analysis for Environmental Monitoring and Nuclear Forensics. IAEA-CN-98/8. International Atomic Energy Agency, Vienna. 
Table I. Categories of nuclear materials

SNM
\begin{tabular}{|l|l|}
\hline IAEA Categories & Characteristics \\
\hline High Enriched Uranium (HEU) & $>20 \%$ U-235 \\
\hline -- Weapons-Grade Uranium (WGU) & $\begin{array}{l}\text { Pure uranium metal } \\
>93 \% \text { U-235 }\end{array}$ \\
\hline Weapons-Grade Plutonium (WGPu) & $\begin{array}{l}\text { Pure plutonium metal } \\
<7 \% \text { Pu-240 }\end{array}$ \\
\hline -- Super-Grade Plutonium (SGPu) & $\begin{array}{l}\text { Pure plutonium metal } \\
<3 \% \text { Pu-240 }\end{array}$ \\
\hline
\end{tabular}

\section{Reactor Fuel}

\begin{tabular}{|l|l|}
\hline IAEA Categories & Characteristics \\
\hline Low Enriched Uranium (LEU) & $<20 \%$ (typically 3-5\%) U-235 \\
\hline Reactor-Grade Plutonium (RGPu) & $\begin{array}{l}\text { Produced in nuclear power reactors } \\
>19 \% \text { Pu-240 }\end{array}$ \\
\hline Fuel-Grade Plutonium (FGPu) & $\begin{array}{l}\text { Produced in nuclear reactors } \\
>7 \% \text { and }<19 \% \text { Pu-240 }\end{array}$ \\
\hline MOX-grade Plutonium (MGPu) & $\begin{array}{l}\text { Recycled from mixed (uranium + plutonium) } \\
\text { oxide fuel } \\
>30 \% \text { Pu-240 }\end{array}$ \\
\hline
\end{tabular}

\section{Radioactive Sources}

\begin{tabular}{|l|l|}
\hline Typical Uses & Common Constituents \\
\hline Medical Diagnostic Sources & Short-lived radioisotopes \\
\hline Radiotherapy Sources & Co-60 and Cs-137 \\
\hline Irradiators/Sterilizers & Co-60 and Cs-137 \\
\hline Radiography/NDT & Ir-192 \\
\hline Gauging & Co-60, Cs-137, Am-241 \\
\hline Radioisotope Thermoelectric Generators (RTG) & Pu-238, Cm-244, and Sr-90 \\
\hline
\end{tabular}


Table II. Suggested sequence for laboratory techniques and methods

\begin{tabular}{|c|c|c|c|}
\hline Techniques/Methods & 24-Hour & One Week & Two Months \\
\hline Radiological & $\begin{array}{l}\text { Estimated total activity } \\
\text { Dose rate }(\alpha, \beta, \gamma, \mathrm{n}) \\
\text { Surface contamination }\end{array}$ & & \\
\hline $\begin{array}{l}\text { Physical } \\
\text { Characterization }\end{array}$ & $\begin{array}{l}\text { Visual inspection } \\
\text { Radiography } \\
\text { Photography } \\
\text { Weight } \\
\text { Dimensions } \\
\text { Optical microscopy } \\
\text { Density }\end{array}$ & $\begin{array}{l}\text { SEM/EDS } \\
\text { XRD }\end{array}$ & TEM (EDX) \\
\hline $\begin{array}{l}\text { Traditional Forensic } \\
\text { Analysis }\end{array}$ & Fingerprints, Fibers & & \\
\hline Isotope Analysis & $\begin{array}{l}\gamma \text {-spectroscopy } \\
\alpha \text {-spectroscopy }\end{array}$ & $\begin{array}{l}\text { Mass spectrometry } \\
\text { (SIMS, TIMS, } \\
\text { ICP-MS) }\end{array}$ & $\begin{array}{l}\text { Radiochemical } \\
\text { separations }\end{array}$ \\
\hline Elemental/Chemical & & $\begin{array}{l}\text { ICP-MS } \\
\text { XRF } \\
\text { Assay (titration, IDMS) }\end{array}$ & $\mathrm{GC} / \mathrm{MS}$ \\
\hline
\end{tabular}

$\mathrm{SEM} / \mathrm{EDS}=$ Scanning Electron Microanalysis with Energy Dispersive Sensor

TEM= Transmission Electron Microscopy

SIMS = Secondary Ion Mass Spectrometry

TIMS= Thermal Ionization Mass Spectrometry

ICP-MS= Inductively Coupled Plasma Mass Spectrometry

$\mathrm{XRF}=\mathrm{X}$-ray Fluorescence Analysis

IDMS= Isotope Dilution Mass Spectrometry

GC/MS= Gas Chromatography / Mass Spectrometry 